www.jmscr.igmpublication.org

Impact Factor 5.244

Index Copernicus Value: 83.27

ISSN (e)-2347-176x ISSN (p) 2455-0450

crossref DOI: _https://dx.doi.org/10.18535/jmscr/v4i11.104

Journal Of Medical Science And Clinical Research

\title{
Cataract Surgery Outcome in Relation to Posterior Capsule Rupture with Vitreous Loss
}

\author{
Author \\ *Dr Ali.A.Taqi AL-Saffar \\ M.B.Ch.B/D.O/CABMS (Ophth) \\ Head of Ophthalmology Unit/Department of Surgery /School of Medicine/ \\ Sulaimani University-Kurdistan/Iraq \\ Email:ali.taqi@univsul.edu.iq
}

\begin{abstract}
Cataract cases one of the most common treatable blindness, age related cataract is the most common cause of cataract and good surgery contributes strongly to patient quality of life

Aims: To find out the frequency of posterior capsule rupture with vitreous loss in extracapsular cataract extraction and in Phacoemulsification techniques.

Settings and Design: A retrospective (descriptive) survey.

Methods and Material: All 2103 patients enrolled are admitted to the hospital for elective cataract surgery Aso eye hospital-Sulaimani city-Kurdistan-Iraq, one day before surgery, full examination systemic and ophthalmologic examination done including slit lamp examination, Tonometry, Ultrasonography and IOLmaster used for calculation of IOL power. Include all elective ECCE and phacoemulsification cataract surgeries
\end{abstract}

Statistical analysis used: Microsoft excels 2007 and 2010.

Results: Total number of cataract patients/eyes for 2009 are 2103 patients/2103 eyes, females 1052 and males 1051 , represent $50.29 \%$ and $49.70 \%$ respectively, $85 \%$ of patients aged 55 years or more and 2061(98\%) of cataract of senile age related type, 1918 eyes (91\%) ECCE has done, 185 eyes (9\%) cases phacoemulsification surgery done. There are 141 eyes with vitreous loss (6.8\%) with ECCE and 10 eyes (5.4\%) with phacoemulsification.

Conclusions: Posterior capsular rupture with Vitreous loss in ECCE was $6.8 \%$ and with phacoemulsification technique was $5.4 \%$

Key-words: Extracapsular cataract extraction); Phacoemulsification; Anterior chamber intraocular lens; Posterior chamber intraocular lens); Foldable intraocularlens; intraocular pressure; Vitreous loss.

\section{Introduction}

The lens is a transparent, biconvex, crystalline structure placed between iris and the vitreous in a saucer shaped depression the patellar fossa. Its refractive index is 1.39 and total power is $15-16$ D. ${ }^{1}$
A cataract is a clouding of the normally clear and transparent lens of the eye, which may prevent a clear image from forming on the retina. Often both eyes are affected. It is one of the leading causes of blindness in the world today, accounting for $50 \%$ of blindness worldwide; it can be 
classified as, congenital cataract, acquired cataract and the age-related cataract. ${ }^{2}$

The World Health Organization (WHO) has defined standards for the outcomes of cataract surgery (Fig. 4.2). There are three categories: Good (postoperative visual acuity outcome better than 6/18); Borderline (visual acuity outcome in the range 6/18-6/60); and Poor (visual acuity less than 6/60). The WHO recommendations for acceptable outcomes at 1 day postoperation are $40 \%$ cases achieving acuity between $6 / 6$ and $6 / 18$ (Good result); $50 \%$ of cases achieving a visual acuity between $6 / 24$ and 6/60 (Borderline result); and no more than $10 \%$ cases at less than $6 / 60$ (Poor result) with half of those due to intraoperative complications. ${ }^{3}$

Cataract surgery is one of the most frequently performed surgical operations. Greater than 1.5 million cataract surgery procedures are performed annually in the United States. Cataract surgery is indicated: To improve quality of life, this depends on the affected person's visual needs and other indications. 4

\section{Manual Cataract Surgery}

When posterior chamber IOLs began to be widely used in the 1980s most surgeons adopted Extracapsular cataract extraction (ECCE), Phacoemulsification "phaco" is the standard method of cataract extraction in developed countries, and in regional centers in most developing countries. ${ }^{5}$

The largest majority of cataracts occur in old age. ${ }^{6}$ Aims: To evaluate ECCE and the phacoemulsification techniques by monitor the frequency of posterior capsule rupture with vitreous loss

\section{Abbreviations}

ECCE-extracapsular cataract extraction, phacophacoemulsification, PCR-Posterior capsule rupture, IOL- Intraocular lens, AC-IOL-anterior chamber intraocular lens, PC-IOL-posterior chamber intraocular lens,IOP- intraocular pressure, ICCE- Intracapsular cataract extraction, PMMA-polymethylmethacrylate, D- Diopter.

\section{Patients and Methods}

A phaco machine was officially introducedin our Government hospital for the first time in 2008. From that time on surgeons gradually switchedfrom ECCE to phacoemulsification cataract surgery and we need to evaluate the efficacy and effectiveness of cataract surgery.

A retrospective study involved all elective unilateral age related (senile) cataract surgery done in the year 2009 in the only governmental hospital, Aso eye hospital in Sulaimaniya city of Kurdistan region in Iraq.

All 2103 patients (2103 eyes) enrolled are admitted to the hospital for elective cataract surgery in Aso hospital one day before surgery, full examination systemic and ophthalmologic examination done including slit lamp examination, Tonometry, Ultrasonography and IOL-master used for calculation of IOL power.

Usually the operation is done under local anesthesia using retro-bulbar anesthesia with the use of Honan balloon or pressure ball to decrease the incidence of retro-bulbar hemorrhage, general anesthesia is less frequently used

Exclusion criteria: 4 Cases of the old technique intra-capsular (ICCE).

\section{Results}

Out of 2103 patients/eyes underwent cataract surgery in2009, 1052 are females and 1051 are males represent approximately50\% each, 1918 eyes $(91 \%)$ ECCE, in 185 eyes $(9 \%)$ cases phaco surgery was done.

Posterior capsular rupture and vitreous loss occurs in 141 eyes (6.7\%)in overall 2103 cataract surgery with vitreous loss from total cataract surgery done in 2009. 


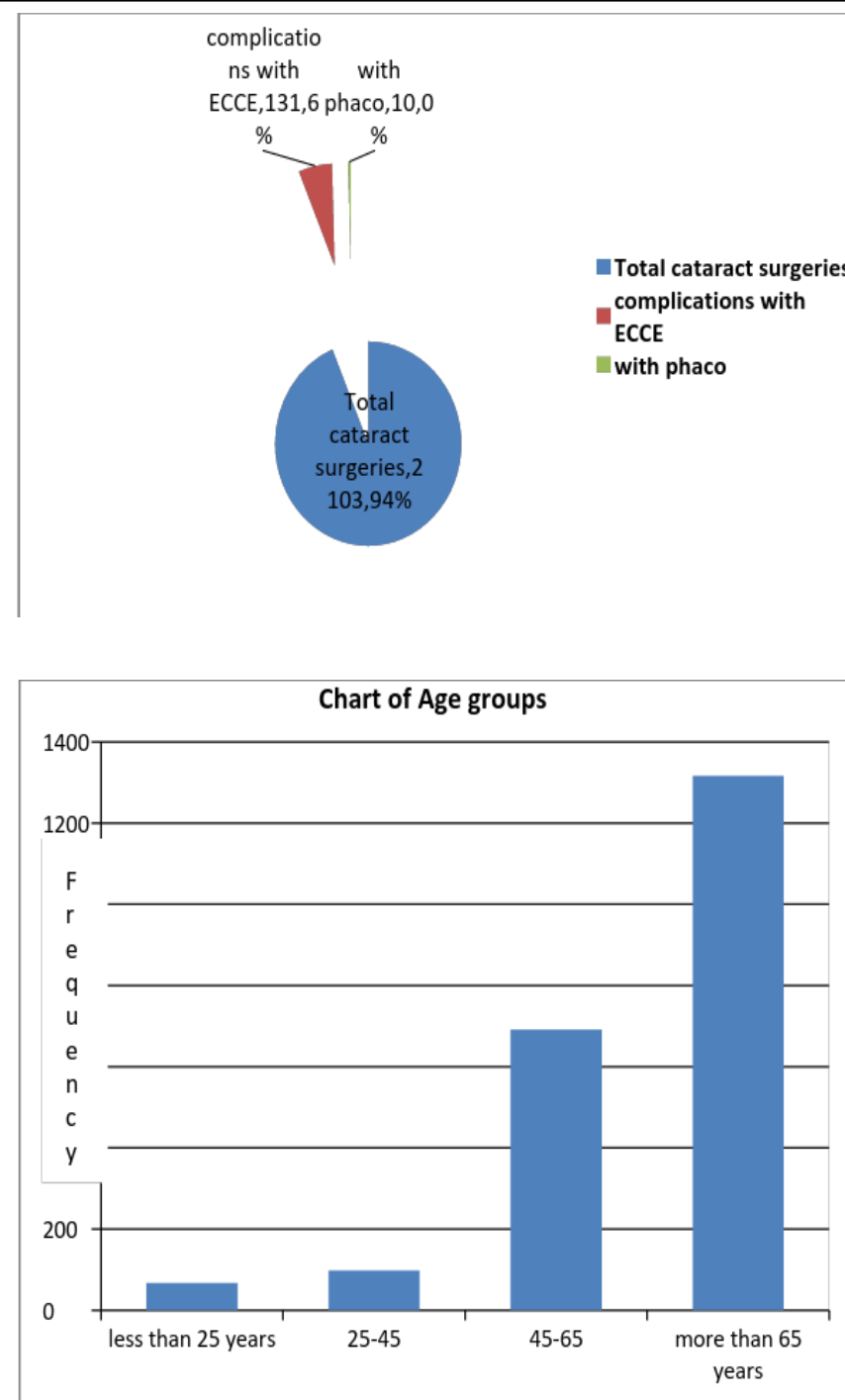

Figure 1: cataract patients age groups (older than 65 years represents $81 \%$ of total patients)

Of overall 141 eyes (6.7\%) with vitreous loss, 131 eyes $(6.8 \%)$ associated with ECCE technique and 10 eyes (5.4\%) associated with phaco-surgery technique.

Regarding type of IOL implanted during ECCE surgery, in 1736 eyes (92.9\%) PC-IOL done successfully while of phaco surgery, 175 eyes (94.6\%) ends successfully with foldable-IOL or PC-IOL, 10 eyes $(5.4 \%)$ are left aphakic

Of the 131 eyes of vitreous loss in ECCE technique, 125eyes $(95.4 \%)$ ends with AC-IOL, 3 eyes $(2.3 \%)$ ends with PC-IOL, and only 3 eyes (2.3\%) left aphakic for secondary IOL implantation later on.

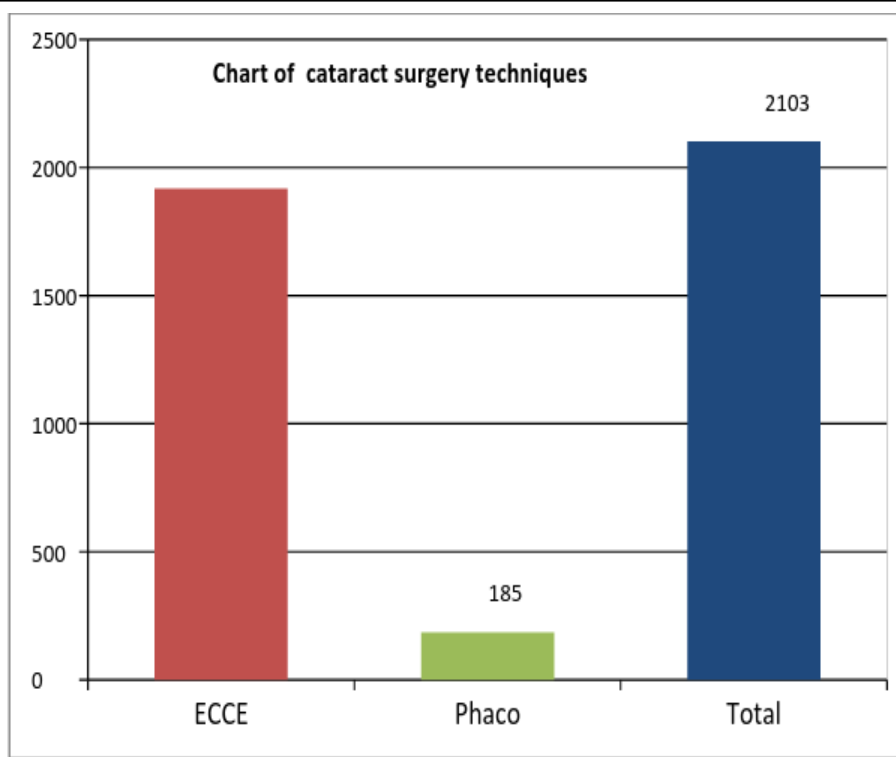

Figure 2: ECCE and Phacoemulsification.

All eyes complicated by posterior capsule rupture and variable amount of vitreous loss were managed by sponge anterior vitrectomy with or without miotics (Acetylcholine).

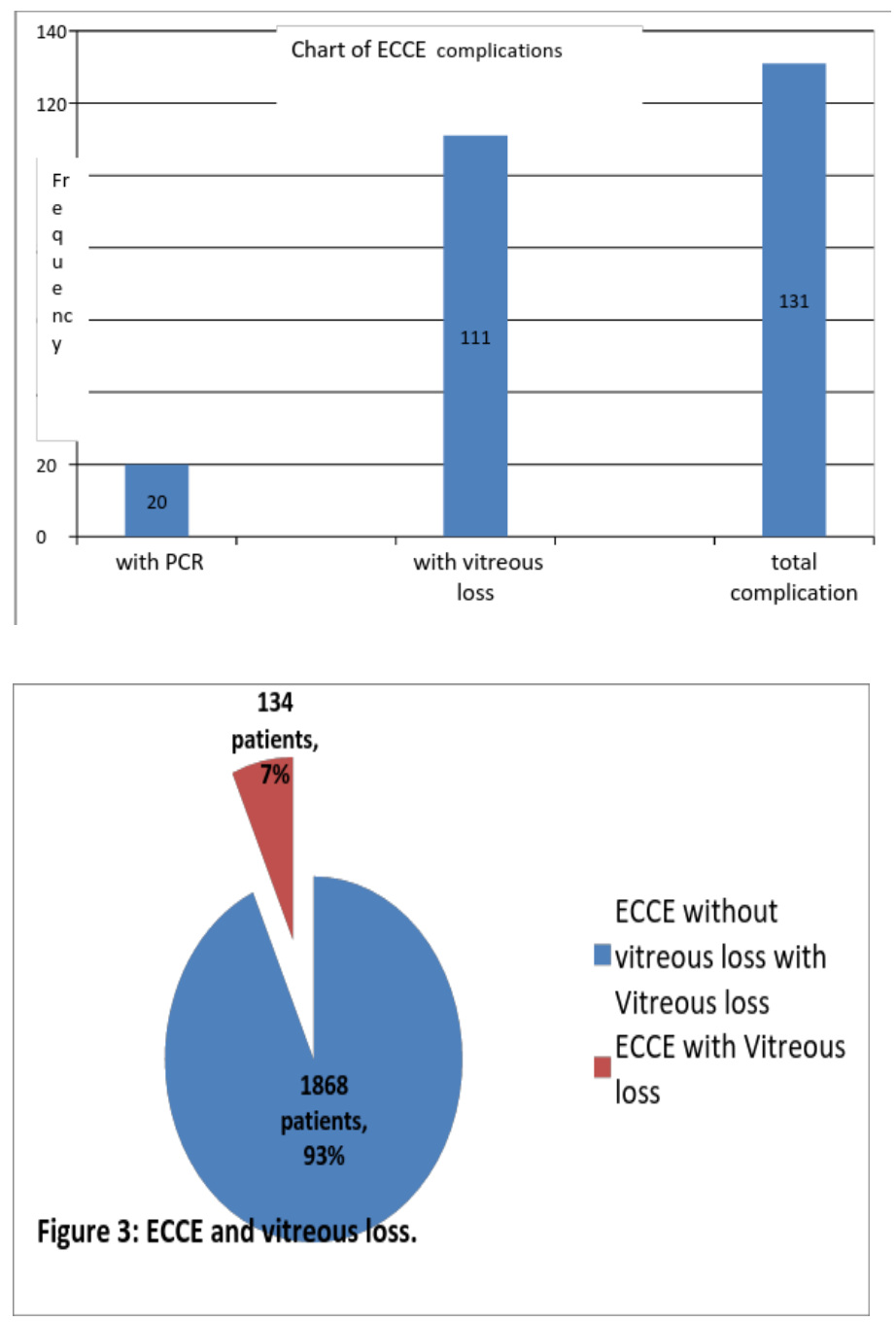



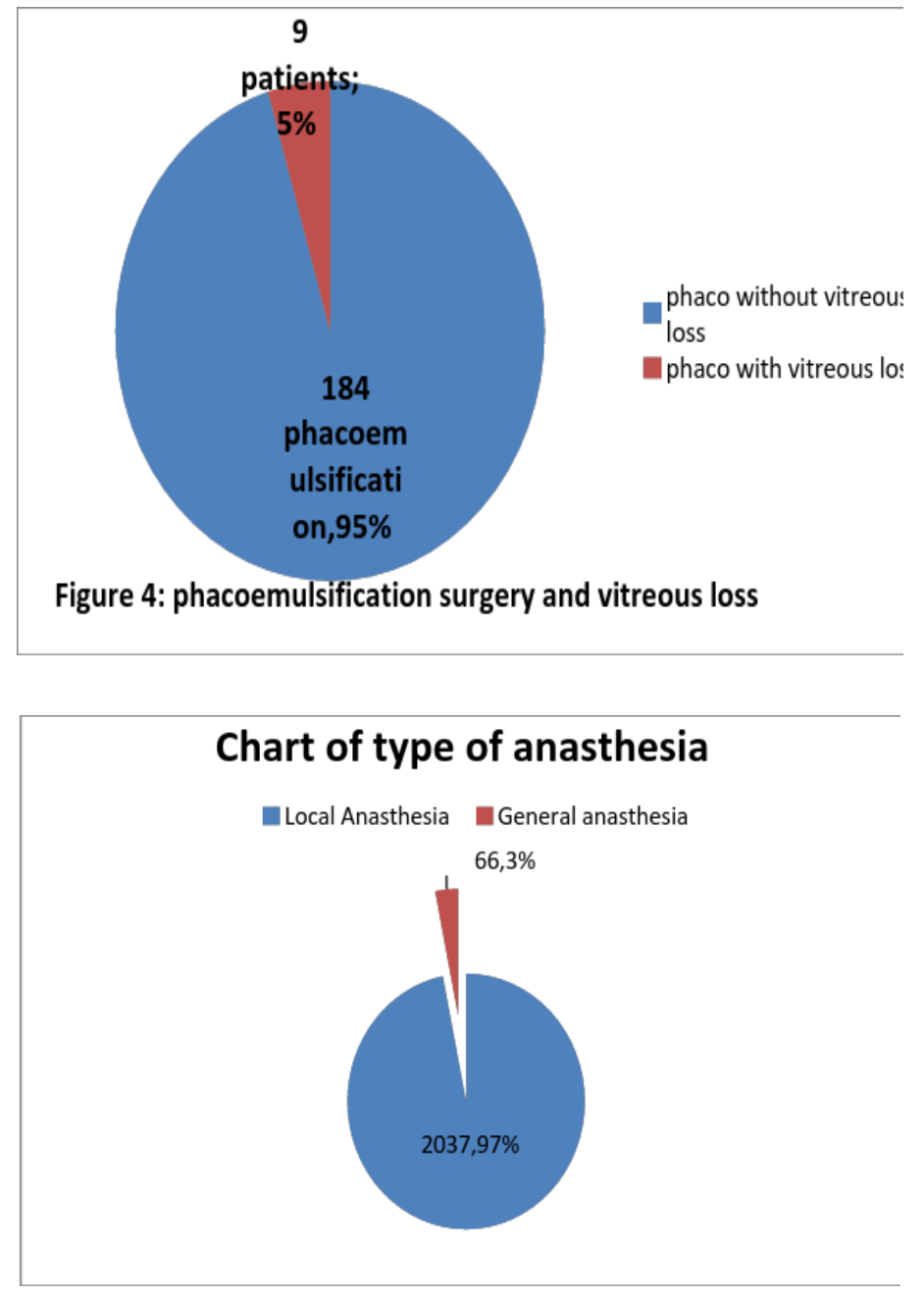

\section{Discussion}

Our overall vitreous loss result is $6.7 \%, 6.8 \%$ with ECCE surgery technique and $5.4 \%$ with phaco surgery technique is close to $5 \%$ rate in Lebanon study. $^{7}$

While it is (2.66\%) in international ophthalmology UK study for evaluation of phaco surgery associated with vitreous loss in district general hospital in $\mathrm{UK}^{8}{ }^{8}$

A rate of $4.5 \%$ in USA study that evaluate the rate of vitreous loss in cataract operated patients by residents. $^{9}$

And finally much better than the $27.35 \%$ in Evaluation of Cataract Surgery Outcome in Western Nigeria. ${ }^{10}$

But still the same as the private hospital evaluation (6\%)in Port Harcourt,Nigeria.

${ }^{11}$ Extracellular fluid accumulation in the fovea causing CME may result in a decrease in visual acuity. Posterior capsular tears and vitreous loss are major risk factors for postoperative CME. ${ }^{2}$

Visual outcomes of Phacoemulsification, visual acuity of 20/40 or better was reported in $92.6 \%$ of eyes undergoing phacoemulsification by thirdyear residents. 98 posterior capsular rupture occurred in $9.9 \%$ and vitreous loss in $5.5 \%$ of the cases. $^{2}$

Rhegmatogenous Retinal Detachment (RRD) is more common in eyes that have undergone cataract surgery complicated by vitreous loss, with the risk of perioperative RRD following vitreous loss increasing up to 10 -fold. ${ }^{2}$

All measures that decrease IOP can be taken to decrease the occurrence of posterior capsule rupture and vitreous loss.

\section{Conclusions}

Still vitreous loss with ECCE technique were high $(6.8 \%)$, but less in Phaco surgery technique $(5.4 \%)$ although it is regarded as new technique.

\section{Recommendation}

Shifting done successfully to phaco surgery technique from the ECCE

It is good to master the two techniques and used each one wisely and when appropriate.

Improve training and machinery of great importance as we are working first with old devices and now we shift to more modern deviceswith continuous training on Good patient preparation.

\section{Acknowledgment}

Aso eye hospital manager and staff of computer department.

Conflict of interest: None

Financial support: None

\section{References}

1. Comprehensive Ophthalmology; chapter 8; p: 167

2. Albert and Jakobiec's principles and practice in ophthalmology; volume 1; chapter 107;section 9; p: 1375. 
3. Ophthalmic Surgery Principles and practice; Spaeth; section II Cataract, chapter4, cataract surgery outcomes; on CD-ROM.2011

4. Primary Care Ophthalmology; cataract surgery, chapter 8 ,

5. Clinical ophthalmology systematic; Kanski; $8^{\text {th }}$ edition, p: 281 chapter 9 the lens.

6. Lecture notes in ophthalmology; Bruce James, $9^{\text {th }}$ edition; 2003, Blackwell, p81

7. Albert and Jakobiec's principles and practice in ophthalmology; vol1; section 9, chapter 114; (CME, post capsular rupture and vitreous loss); p: 140.

8. Visual Outcome In phacoemulsification; chapter 114; p: 1461.

9. Section 9; chapter; Albert and Jakobiec's principles and practice in ophthalmology; volume $1 \mathrm{p}$ : 1556.

10. Evaluation of Cataract Surgery Outcome in Western Nigeria M A Isawumi, ${ }^{1}$ EO Soetan, ${ }^{2}$ AO Adeoye, ${ }^{1}$ and C O Adeoti ${ }^{3}$, Ghana medical journal,2009.

11. Audit of visual outcome of cataract surgeries in a private eye hospital in Port Harcourt, Nigeria/ Chibuike Sydney Ejimadu, Chinyere N Pedro-Egbe Department of Surgery, Faculty of Clinical Sciences, University of Port Harcourt, Port Harcourt, Nigeria. 